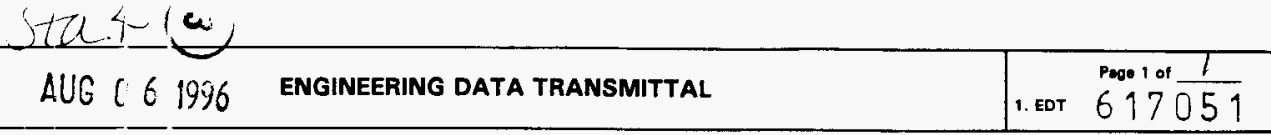

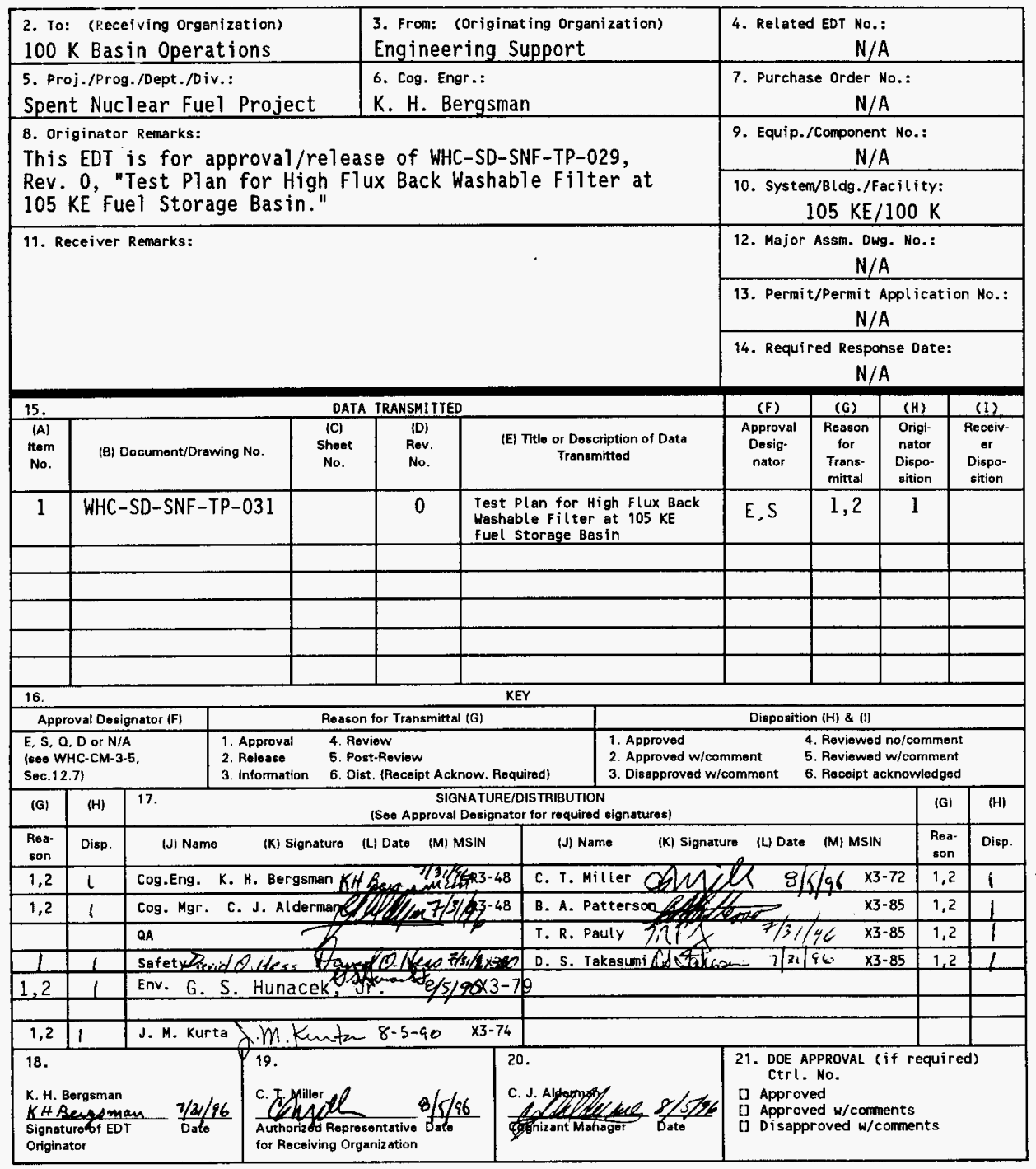

BD-7400-172-2 (04/94) GEF097 


\title{
Test Plan for High Flux Back Washable Filter at 105 KE Fuel Storage Basin
}

\author{
G. J. Sevigny \\ J. H. Konynenbelt \\ K. H. Bergsman \\ Westinghouse Hanford Company, Richland, WA 99352 \\ U.S. Department of Energy Contract DE-AC06-87RL10930
}

$\begin{array}{lll}\text { EDT/ECN: } & 617051 & \text { UC: } 600 \\ \text { Org Code: } & 2 C 500 & \text { Charge Code: LBO11 } \\ \text { B\&R Code: } & \text { EW3135040 } & \text { Total Pages: } \not 2 \text { i3 kms \&/4/4C }\end{array}$

Key Words: Integrated Water Treatment System, Test Plan, Back Washable Filter

Abstract: This document describes the operational testing at the KE Basin planned for demonstrating and evaluating a high flux back washable filter. The document includes the description of the operational testing to be conducted, the samples and measurements to be taken, the sample analysis to be performed, and the use of the information obtained.

TRADEMARK DISCLAIMER. Reference herein to any specific comercial product, process, or service by trade name, trademark, manuf acturer, or otherwise, does not necessarily constitute or imply its endorsement, reconmendation, or favoring by the United States Goverment or any agency thereof or its contractors or subcontractors.

Printed in the United states of Arerica. To obtain copies of this document, contact: WhC/BCS Document Control Services, P.O. Box 1970, Mailstop H6-08, Richland WA 99352, Phone (509) 372-2420; Fax (509) 376-4989.
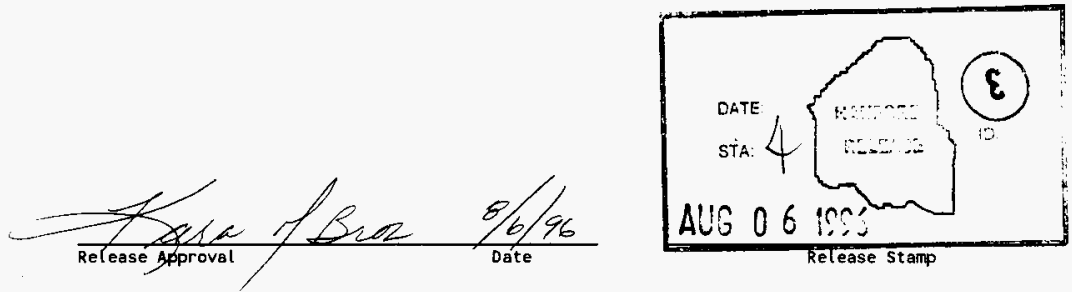

\section{Approved for Public Release}


WHC-SD-SNF-TP-031 REV. 0

TEST PLAN FOR HIGH FLUX BACK WASHABLE FILTER AT 105 KE FUEL STORAGE BASIN

Contents

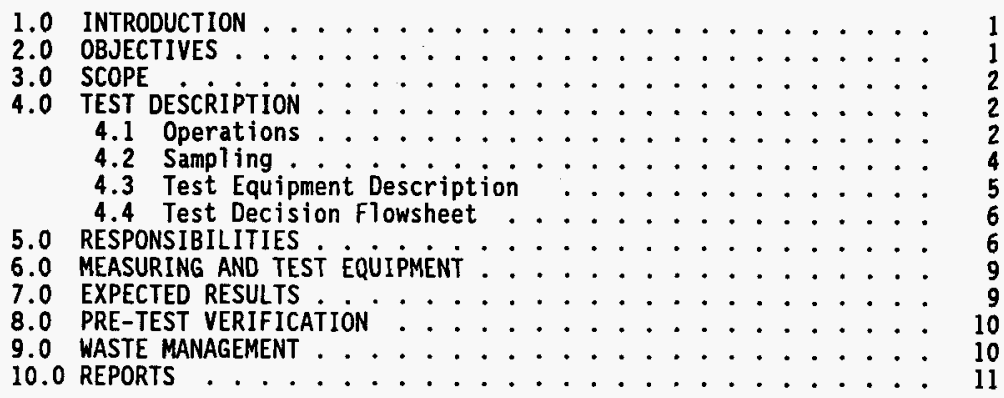




\subsection{INTRODUCTION}

The Spent Nuclear Fuels Project is evaluating filtration systems to maintain water quality in the $105 \mathrm{KE}$ fuel storage basin during the removal of spent nuclear fuel from the basin. A high flow rate of water through the filter is required to maintain the basin clarity. However, the basin operating area is limited and large filter systems would be undesirable. A relatively small filter system with a $500 \mathrm{gpm}$ flow rate has been located and is available for testing. This test is to determine if the filter has adequate filtration efficiency to maintain basin clarity while generating only a reasonable amount of secondary waste, and requiring minimal maintenance. The filter will be operated during this testing by PN Services, the company that owns the filter. Westinghouse Hanford Company (WHC) work document 1K-96-699/W covers installation, permitting, and safety documentation.

\subsection{OBJECTIVES}

The overall objectives of this activity are to demonstrate and evaluate a high flux back flushable filter. The high flux (i.e., high flow rate per unit area of filter media) is desired to minimize the plant-unit's footprint.

Information gathered during the test will be used to design and specify a full scale filtration unit for the basin.

The specific objectives are listed below:

Demonstrate/evaluate the operation of a full scale automated backwash filter system in the basin environment;

Identify at least one filter rating that is both practical and effective for: 1) producing clear water (the filters must operate with a minimum of operator attention, while producing filtered water that is clear enough to provide at least 15 feet of working visibility); and 2) removing particulate alpha contamination (a filter rating capable of reducing total alpha by a factor of three or more would extend IXM life);

Confirm adequate operation of the filters after multiple loading/back flush cycles by estimating filter life.

Gather data on filter pressure drops versus total gallons of turbid water processed (i.e., differential pressure versus time at a constant flow) between each backwash cycle;

Gather data on frequency of back flush cycles (What percentage of the total filter throughput will the back wash represent?); 
WHC-SD-SNF-TP-031 REV. 0

\subsection{SCOPE}

The scope of the test will allow for testing of a $500 \mathrm{gpm}$ (nominal rating) filter system under actual basin operation conditions. The conditions will include water from areas in the basin adjacent to canister cleaning operations, and, possibly, other ongoing operations that are likely to provide elevated turbidity. The duration of the operations will be approximately 120 hrs of operation during normal working hours (two shifts a day/five days a week). The filter will be tested at two flow rates (approximately 500 and 200 gpm respectively) up to the differential pressure recommended by the vendor. The filter will be operated through many back flush cycles under a variety of solids loading conditions to determine the filter's ability to clarify the water and operate for an extended period of time. The initial test configuration will include one filter with a nominal rating on the order of 1 or 2 microns, and one filter with a nominal rating in the 4 to 6 micron range. These two different filter ratings will be tested and compared against each other as the automatic back flush system alternately switches from one to the other over a number of cycles.

During operation, the filter system will be monitored for inlet flow rate, differential pressure, turbidity on the inlet and outlet streams, and back flush frequency. Turbidity will also be monitored by visual observation of markers submerged in the pool near the filter discharge. Samples will be taken from the inlet and outlet streams to determine the filter's water decontamination efficiency (total alpha and cesium reduction), and to confirm on line turbidity measurements. Note that the plan to test two different filter ratings in a given test run will require that the discharge samples of one filter element be kept apart from those of the other element.

Testing under additional conditions will be evaluated by the Test Engineer and the Design Authority. Depending on how the initial filter elements perform, the Test Engineer (with concurrence from the Design Authority) may decide to proceed with further testing (with, or without changes to flow rates, back wash set points, etc.) using both of the initial elements, only one of the initial elements, two new elements of intermediate size, or some combination of the above.

Note: If any of the specified operating conditions can not be met, or any of the designated samples or data can not be taken, the Test Engineer has the authority to revise the test conditions and continue the test.

\subsection{TEST DESCRIPTION}

\subsection{Operations}

The test will be performed with the filter system in a greenhouse in the north truck bay of the 105K East Load Out Area. The filter system will be evaluated by operating the system with basin water from areas where visibility 


\section{WHC-SD-SNF-TP-031 REV. 0}

improvements would benefit operations. A long intake hose/pipe will be located in the basin a minimum of 3 feet above the basin floor. A discharge hose/pipe will be located in the basin in an area of minimal activity well above the bottom and pointed in a horizontal direction to prevent disturbance of floor sludge. The discharge will occur over a target plate with underwater lights above and below the target to assess visibility. The target will be attached to a long pole suspended from the deck. A video tape recording will be made of the area during operations to provide qualitative clarity data and assist in correlating turbidity measurements. The normal flow rate to the filter will be approximately $500 \mathrm{gpm}$ and be controlled by the filter system. At least one other flow rate of approximately $200 \mathrm{gpm}$ will be tested. The actual flow rate will be determined by PN Services. While there is considerable latitude in selecting the exact flow rate at which a given test may be run, it is necessary to maintain that flow as constant as reasonably possible (e.g., within plus or minus $10 \%$, if possible) during the test, in order to ensure that the differential pressure data is meaningful. During testing, PN Services will record data on Data Sheet 1 during any significant changes, including back flushes, or a minimum of once an hour. An automatic data logger will be used to collect data on a more frequent basis.

A target provided by PNNL will be attached to a long pole suspended from the deck. The target will have various symbols marked somewhat like an eye chart to assist in assessing visibility. The lighting in the area should be similar to the lighting used for canister washing or other bas in activities. A remotely operated VCR provided by Westinghouse Hanford Company (WHC) will be used to record the image of the target on an hourly basis, or more frequently if significant events may affect the basin clarity.

The test will start using relatively turbid basin water and later shift to collecting less turbid water. After the leak test specified in the work document, the initial operating settings will be established and recorded in the data sheets, the system will be allowed to operate while monitoring turbidity, visual clarity at the filter discharge, and back flush frequency. If operation of the filter does not clarify the water or if the filter plugs rapidly, the test will be stopped, and the situation will be evaluated. In general, a decision to change a parameter will follow the logic outlined in the decision flow sheet (section 4.3). The changes will be made upon agreement between the test engineer and the vendor.

Radiation dose measurements will be made periodically during the course of the test to check for the accumulation of radionuclides in the filter. The dose rate from the filter is not expected to be high because thick filter cakes are not typically collected and sludge will not be collected from the floor.

The filter pump pulls water from the basin and pushes the water through one of the filters at a time. Filter operation is switched by automated valves when a back flush is needed, as determined by the differential pressure set point. The back flush is accomplished without interruption of the inlet water flow. The filters will operate unless basin conditions deteriorate because of the 


\section{WHC-SD-SNF-TP-031 REV. 0}

filter operation. As mentioned earlier, the initial water will come from the center basin and the filter will operate for three hours before collecting turbid water.

The initial operating condition will be:

Flow Rate:

Operating filter nominal ratings:

Back flush initiation pressure:

The second operating condition will be:

Flow Rate:

Operating filter nominal ratings:

Back flush initiation pressure:
Approximately $200 \mathrm{gpm} \pm 100 \mathrm{gpm}$ 1 to 2 micron and 4 to 6 micron $15 \pm 3$ psig

Note: Although the above testing conditions allow considerable latitude in selecting the exact flow rate at which a given test will be run, once the flow rate has been selected it must be maintained as constant as reasonabiy possible (e.g., within plus or minus $10 \%$, if possible) during the test, in order to ensure that the differential pressure data is meaningful.

Initial pressure drops across the clean filter elements are expected to be less than 5 psig. The anticipated backflush volume is approximately 60 gallons, based on the volume of the backflush blow cases. The desired flow rates are $200 \mathrm{gpm} \pm 20 \mathrm{gpm}$ for the first set of conditions and $500 \mathrm{gpm} \pm 25$ $\mathrm{gpm}$ during the second set of conditions. None of these anticipated or desired conditions is a requirement of the test.

Additional operating conditions may be evaluated in subsequent tests. Operating parameters of the subsequent tests will be determined by the Design Authority and the Test Engineer, and are not limited to the ranges of the initial operating conditions.

\subsection{Sampling}

The PN Filter skid has sample ports on the inlet and outlet streams, and the back flush line. Samples of the filter inlet and outlet will be collected during the test to assist in filter evaluation; no back flush sampling is currently planned. Initial samples should be taken within 10 minutes, or as soon as possible after startup, to confirm adequate filtration, as requested by Basin Operations.

After start up, at least one sample of the filter skid inlet and one sample of the active filter outlet will be taken during each filtration cycle, unless the filtration cycles become too short. The Test Engineer will establish an appropriate point during the filtration cycles to take the sample. As a minimum, samples should be taken once per shift. The goal is to take the sample following each backwash cycle after the new filter cake has reestablished itself and the flow rate has stabilized. The samples may be 
WHC-SD-SNF-TP-031 REV. 0

taken as individual manual grab samples, manual composite of grab samples, or automatic composite samples. If composite samples are taken, the composite collection receptacle will be changed out and replaced with a fresh one approximately once every two days. Note that, if composite samples are utilized, the discharge stream samples from one filter element must be kept apart from those of the other filter element, unless the two filter elements being used have the same pore size rating.

Additional samples from the inlet and outlet will be taken whenever inlet or outlet turbidity conditions change significantly or as directed by the Test Engineer.

\section{Responsibilities}

PN Services will draw all samples.

SNF Operations will supply the sample containers, appropriate chain of control labels, and provide shipping to the designated lab after the samples have been drawn.

The Test Engineer will designate the laboratory, receive the data from the laboratory, and distribute it to the appropriate personnel.

A contact dose rate of each sample bottle, shall be documented and supplied to the Test Engineer before the bottles are shipped.

The following information is required and will be obtained by the laboratory to evaluate the filter operations from the inlet and filtrate (outlet) samples:

On all samples:

- Total alpha

$-{ }^{137} \mathrm{Cs}$

On a limited number of samples

- Turbidity

- Total undissolved solids

- PCB in undissolved solids per electron capture method

Any sampling required for the purposes of waste characterization and disposal are described in the PN Filter Testing Project Waste Management Plan, WMP-0896.

\subsection{Test Equipment Description}

The equipment piping and instrument diagrams will be provided by PN Services. The filtration system consist of:

Pneumatically actuated valves, 
WHC-SD-SNF-TP-031 REV. 0

PLC control system,

8" flanged inlet and outlet lines,

4" back flush line,

pneumatically pressurized accumulator (approx. 60 gallons- used for back flush at 60 PSI),

Filter pressure transmitters to determine filter differential pressure,

Flow rate and turbidity meters.

The filter system is mounted on a transportable skid approximately $8^{\prime} L X 8^{\prime} W$ $X 7^{\prime} H$. The filter system has two filters, a back flush ballast tank, flanged iniet and outlet piping, and control valves for operation.

\subsection{Test Decision Flowsheet}

A decision flowsheet (figure 1) has been generated to reduce the number of operational variables as operating characteristics are obtained during the test. The decision flow sheet is intended to reduce test time and the potential for filter change-outs by providing testing logic.

\subsection{RESPONSIBILITIES}

The filtration unit vendor will be responsible for supplying a skid mounted filtration system with the following features:

Back flushable filter housings, initially provided with one filter element with a 1 to 2 micron nominal rating (corresponds to an absolute rating of about 4 to 8 microns) and one filter element with a 4 to 6 micron nominal rating.

The filter elements will be removable from the housing so that filter elements with different ratings can be tested if needed.

Provide two (2) additional filter elements with nominal ratings of approximately 2 to 4 microns for testing if the first elements are inadequate.

Secondary confinement of liquids spills from the skid;

Back flush system (water blow case, automatic valves, pressure and flow instrumentation, programmable controller, etc.) that is located on the skid;

HEPA filters on any vents to atmosphere;

Test instrumentation for inlet flow rate, differential filter pressure, inlet and outlet turbidity measurements, and equipment for obtaining composite samples;

Pump and hose/pipe to draw water from the main basin, circulate that water through the filters, return filtered water to the main basin, and direct back flush streams to the Weasel Pit; 
WHC-SD-SNF-TP-031 REV. 0

Data Sheet 1 - Filter Test Data

\begin{tabular}{|l|l|l|l|l|l|l|l|}
\hline \multicolumn{7}{|l|}{ PN SERVICES FILTER TEST DATA } & \\
\hline Initials & hr:min & & & & & & \\
\hline time & gpm & & & & & & \\
\hline Flow Rate & gpm & & & & & \\
\hline $\begin{array}{l}\text { Piff. } \\
\text { filter A A }\end{array}$ & psi & & & & & & \\
\hline $\begin{array}{l}\text { diff. } \\
\text { Pressure } \\
\text { filter B }\end{array}$ & psi & & & & & & \\
\hline $\begin{array}{l}\text { inlet } \\
\text { turbidity }\end{array}$ & NTU & & & & & & \\
\hline $\begin{array}{l}\text { outlet } \\
\text { turbidity }\end{array}$ & NTU & & & & & & \\
\hline $\begin{array}{l}\text { hours since } \\
\text { back flush }\end{array}$ & hours & & & & & & \\
\hline $\begin{array}{l}\text { cumulative } \\
\text { back flushes }\end{array}$ & no. & & & & & & \\
\hline $\begin{array}{l}\text { Back flush } \\
\text { set point }\end{array}$ & psi & & & & & & \\
\hline $\begin{array}{l}\text { Back flush } \\
\text { vol. setting }\end{array}$ & gallons & & & & & & \\
\hline $\begin{array}{l}\text { filter A } \\
\text { rating }\end{array}$ & micron & & & & & & \\
\hline $\begin{array}{l}\text { filter B } \\
\text { rating }\end{array}$ & micron & & & & & & \\
\hline $\begin{array}{l}\text { filter A } \\
\text { dose rate }\end{array}$ & mrad/hr & & & & & & \\
\hline $\begin{array}{l}\text { filter B } \\
\text { dose rate }\end{array}$ & mrad/hr & & & & & & \\
\hline $\begin{array}{l}\text { Outlet } \\
\text { visibility }\end{array}$ & $\begin{array}{l}\text { smallest } \\
\text { visible }\end{array}$ & & & & & & \\
\hline
\end{tabular}


WHC-SD-SNF-TP-031 REV. 0

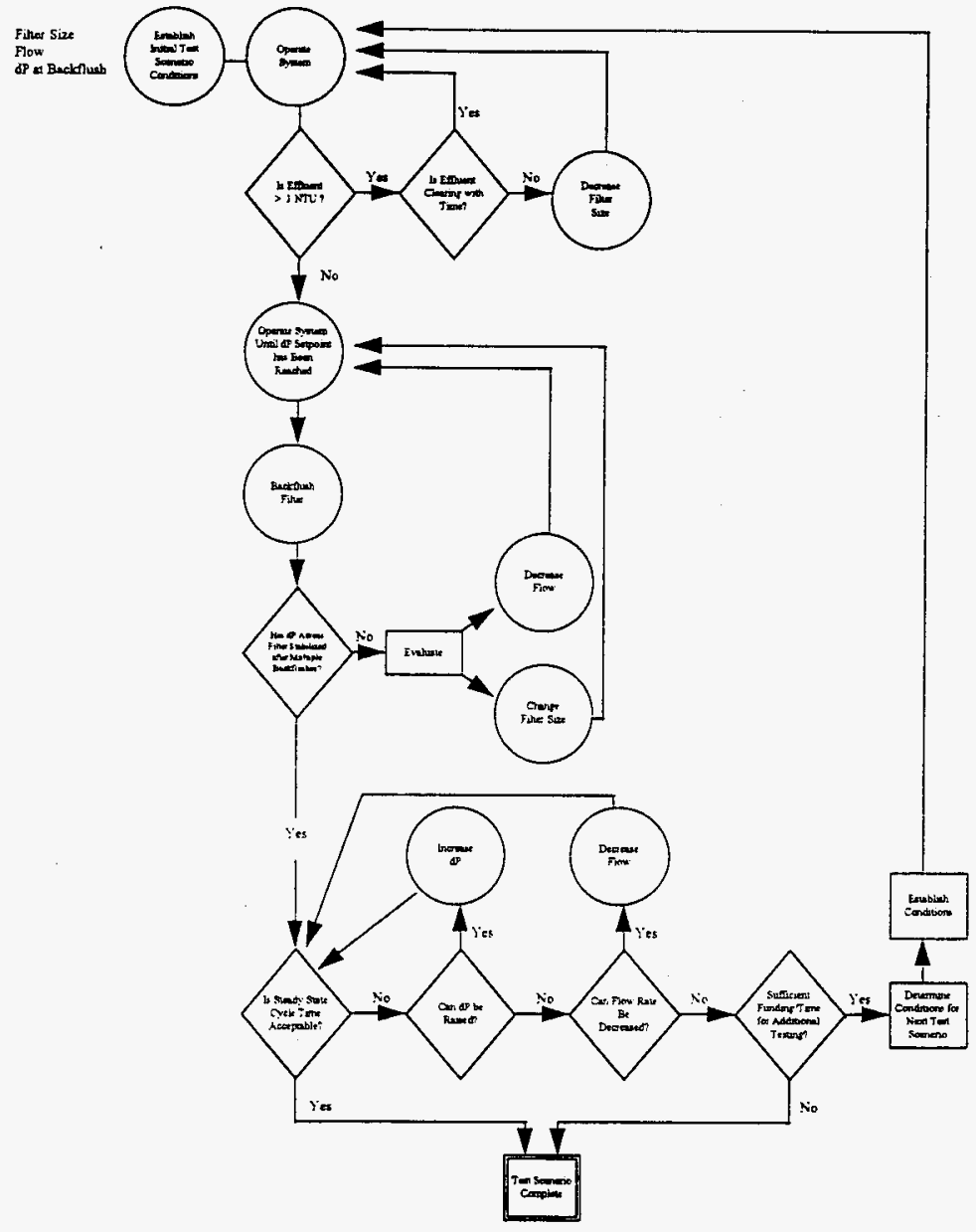

Figure 1. Decision Flowsheet for PN filter Test at KE 105 Basin. 


\section{WHC-SD-SNF-TP-031 REV. 0}

NOTE: The filter back flush stream should contain only water and entrained particulate (i.e., minimal amounts of entrained air), and the total volume and the maximum flow rate should be minimized to minimize mixing in the pool. The back flush should exit through a diffuser like a slotted pipe.

The vendor will also supply compressed air and an electrical generator which will be located outside the basin. Any facility modification required to connect the air and power to the vendor's equipment will be completed by WHC staff.

The vendor will supply operating personnel with radiation worker qualification to set up and operate the filtration system.

The K-basin operations personnel will be responsible for:

Supplying radiological control technicians and personnel for positioning the inlet and discharge hoses/pipes and making visual observation of the area around the filter discharge.

Scheduling testing activities.

Providing lighting and the video camera for monitoring activities.

\subsection{MEASURING AND TEST EQUIPNENT}

A11 measuring and testing equipment will be supplied by the vendor with the exception of radiation monitoring equipment and cameras. The measuring equipment will include light scattering turbidity monitors measuring in NTU, flow monitors, differential pressure elements, and relay counters to count back flushing frequency. Accuracy of the instrumentation will be responsibility of the vendor but is expected to be verifiable and be accurate to at least $10 \%$ of the reading. Operations will take samples to correlate the turbidity measurements. Additional radiation monitoring may be performed external to the system as a secondary means of verifying efficiency based on costs and schedule.

\subsection{EXPECTED RESULTS}

The results from the testing will indicate the viability of a back flushable filter with a high flux rate. The filter is expected to initially operate with infrequent back flushes and the complete recovery of the initial differential pressure after back flushing. After many cycles the back flushing frequency is expected to increase allowing an extrapolation for extended periods. The recovery after back flushing is expected to be reduced and a nonrecoverable pressure drop will increase over the life of the filter. Based on the testing, a qualitative estimate of the filter life can be made by 
the design organization. The results are also expected to show the filter can: 1) reduce the turbidity of the water, and thereby improve the visibility of the water in the basin with minimal maintenance; and 2) remove enough TRU from the water to extend IXM 1 ife and improve product water quality.

A successful test will be determined by the following:

The back flush volume constitutes less than a $1 \%$ of the throughput between back flushes,

The pressure drop after each back flush increases less than $0.1 \%$ of the differential pressure set point for initiating the back flush, on average.

The filtrate turbidity is less than 1 NTU and visibility is confirmed by observation and readability of the submerged target.

The filtrate total alpha concentration is less than one third of the inlet total alpha.

The filter operates automatically with no maintenance during the tests or extensive manual manipulation.

The flow rate is at least $200 \mathrm{GPM}$ for an hour with a differential pressure less than 40 psi.

\subsection{PRE-TEST VERIFICATION}

The filter is already contaminated from previous testing. Therefore, pretest verification will be minimized. The filter unit checked out for proper electrical connections, motor rotation, and back flush operation will be performed before it is installed in the basin building. The turbidity meters will be checked outside the filter system for operability. Prior to pumping water from the pool the system will be hydro tested as practical up to the inlet and outlet valves on the system. After the filter is check for leaks and installed in the basin area, it will be tested using clear water near the basin surface before testing with turbid water. The WHC shall verify the system has been adequately pretested before beginning the filtration testing.

\subsection{MASTE MANAGEMENT}

No significant secondary waste streams are expected during the test. Any waste generated would be disposed of by the WHC KE operation group along with normal waste disposal activities. The filters will be back flushed with clean water at the completion of the test. The SNF Project will be responsible for disposition of the filters (by KE Operations) in ECOROC containers after they are back flushed and removed from the skid by PN Services personnel. 


\section{WHC-SD-SNF-TP-031 REV. 0}

\subsection{REPORTS}

The vendor will complete a report summarizing the results of the test and compare the results to previous operation. This vendor report will be combined with a Hanford project report prepared by personnel supporting the test. The report will contain operating data, observations, and a discussion of operations in the pool at the time of the test. The report will also discuss the expected life of the filters and improvement in clarity that might occur from a $1000 \mathrm{gpm}$ system during future operations. 


\begin{tabular}{|c|c|c|c|c|c|}
\hline \multicolumn{6}{|c|}{ DISTRIBUTION SHEET } \\
\hline & \multirow{2}{*}{\multicolumn{3}{|c|}{$\begin{array}{l}\text { From } \\
\text { Engineering Support }\end{array}$}} & \multicolumn{2}{|l|}{ Page 1 of 1} \\
\hline Distribution & & & & \multicolumn{2}{|c|}{ Date August 6, 1996} \\
\hline \multicolumn{4}{|l|}{ Project Title/Work Order } & \multicolumn{2}{|c|}{ EDT No. 617051} \\
\hline \multicolumn{4}{|c|}{$\begin{array}{l}\text { Test Plan for High Flux Back Washable Filter at } 105 \text { KE Fuel } \\
\text { Storage Basin }\end{array}$} & \multicolumn{2}{|l|}{ ECN No. N/A } \\
\hline Name & MSIN & $\begin{array}{c}\text { Text } \\
\text { With All } \\
\text { Attach. }\end{array}$ & Text Only & $\begin{array}{l}\text { Attach./ } \\
\text { Appendix } \\
\text { Only }\end{array}$ & $\begin{array}{l}\text { EDT/ECN } \\
\text { Only }\end{array}$ \\
\hline $\begin{array}{l}\text { C. J. Alderman } \\
\text { K. H. Bergsman } \\
\text { S. P. Burke } \\
\text { D. 0. Hess } \\
\text { V. L. Hoefer } \\
\text { G. S. Hunacek, Jr. } \\
\text { J. H. Konynenbelt } \\
\text { J. M. Kurta } \\
\text { C. T. Miller } \\
\text { B. A. Patterson } \\
\text { T. R. Pauly } \\
\text { C. C. Pitkoff } \\
\text { D. S. Takasumi } \\
\text { P. A. Scott } \\
\text { G. J. Sevigny } \\
\text { D. L. Sherre11 } \\
\text { K Basins Project File } \\
\text { SNF Project File }\end{array}$ & $\begin{array}{l}\text { R3-48 } \\
\text { R3-48 } \\
\text { X3-74 } \\
\text { X3-80 } \\
\text { R3-11 } \\
\text { X3-79 } \\
\text { K7-97 } \\
\text { X3-74 } \\
\text { X3-72 } \\
\text { X3-85 } \\
\text { X3-85 } \\
\times 3-85 \\
\text { X3-85 } \\
\text { R3-87 } \\
\text { P7-41 } \\
\text { R3-86 } \\
\text { X3-85 } \\
\text { R3-11 }\end{array}$ & & & & \\
\hline
\end{tabular}

